\title{
ANALYSIS OF PHASE CHANGES OF HEAT TREATED BLAST FURNACE COKE
}

\author{
Anna KONSTANCIAK \\ Czestochowa University of Technology, Faculty of Production Engineering and Materials Technology, \\ Czestochowa, Poland, EU, konstanciak.anna@wip.pcz.pl
}

https://doi.org/10.37904/metal.2019.991

\begin{abstract}
The article presents structural changes of blast furnace coke. Mass proportions of the crystalline phase of coke before the blast furnace process and after heat treatment are presented. For this purpose, studies were carried out using the Seifert X-ray diffractometer. The crystallite dimensions were determined - width, height and interplanar distance. The crystallinity coefficients were calculated. The nanoporosity structure on the surface and inside the coke pieces was determined for selected samples. The structural tests were compared with coke test results after the processes under variable temperature conditions.
\end{abstract}

Keywords: Metallurgy, coke for blast furnace, SAXS method, structural tests, crystallinity of coke

\section{INTRODUCTION}

Carbon as a chemical element occurs as three basic allotropes, namely: diamond, graphite and fullerene. The fine-crystalline variety is commonly known as an amorphous carbon. An important characteristic that influences the coking process of coals is the degree of carbonization of the input material. Due to this reason therefore bituminous coals in the ranks of 34-36 are the most frequently used.

A unit cell of graphite has certain parameters, namely: distances between neighbouring atoms in a single layer are $0.1415 \mathrm{~nm}$, while between the layers of $0.3354 \mathrm{~nm}$, and the angle between bonds of $120^{\circ}$.

Black coal applied for coke production demonstrates two crystal structures, known as the hexagonal and rhombohedral structures. The rhombohedral structure is thermodynamically unstable. In general, graphite contains less than $40 \%$ of rhombohedral graphite. Therefore, it is produced by shear deformation of hexagonal graphite. The rhombohedral sequence structures at the temperature of above $1600 \mathrm{~K}$ transform progressively to the hexagonal modification $[1,2]$.

The coke is produced under reactions that take place during pyrolysis of carbon by carbonaceous substance which undergoes decomposition during heating. The complex nature of this process, caused by the heterogeneity and complex structure of coals, makes that the mechanism of this process itself is not clearly defined. In order to explain this phenomenon many theories have been developed so far. Idealizing the process of coke production, thermal decomposition can be assumed as a chain of subsequent processes. At this basis proceeds carbon pyrolysis reaction, and the final product is a solid with complex structure (coke) [3].

\section{THE ROLE OF COKE IN THE BLAST FURNACE}

During processing in the blast furnace, coke serves several functions, namely as a fuel, an ore reducer and a coal carburizer. It should contain the lowest possible level of pig iron admixtures, such as sulphur and phosphorus. It serves as a skeleton, ensuring good gas permeability of the batch in the blast furnace zones. The quality of this instrument is ensured, when it is built mostly from lumps having the grain between 40 and $60 \mathrm{~mm}$. As far as it is possible, these lumps should be kept in the furnace until they are combusted in front of the nozzles. The durability of lumps should result from their resistance to both cold and hot. Its low reactivity is also desirable. Thermal interactions reduce strength properties of the coke due to changes in the internal stresses of the structure. It is also caused by the presence of mineralogical and organic inclusions in coals 
being subject to coking. The thermal conductivity of coke increases as the content of volatile matter decreases. As volatiles are released from coke, a loss and contraction of the solid occurs, which leads to a decrease in the strength. The surface layer of the coke grain wears off due to gasification (A zone) (Figure 1). This process, however, continues - oxidizing the inner pores. The wall thickness between pores of the coke grain is reduced. Some components are subject to selective oxidation. This causes deterioration of the inner zone $\mathrm{B}$. It becomes easily abradable by external factors. This results in dust formation. Being deteriorated by internal stresses and the graphitization process, the coke grain $C$ goes up to the level of nozzles, namely it reaches the combustion chamber [3,4].

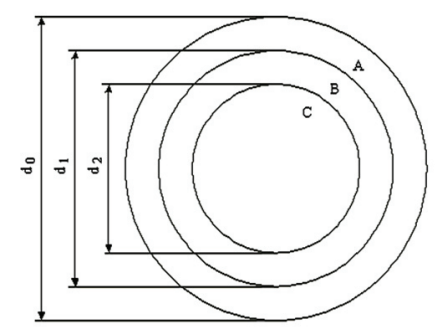

Figure 1 Scheme of oxidation of coke granule [3]

\section{STRUCTURAL STUDIES OF THE BLAST-FURNACE COKE}

Ash and its components are crucial in coke. It is not just about its characteristic as a carbon reducer, but it is also important due to the fact that at the temperature exceeding $1300^{\circ} \mathrm{C}$, the coke ash plays no longer the role of connector in the coke structure and it transfers into a liquid that weakens the coke channels. This was confirmed, among others, by thermal-conductivity tests (quality assessment analysis) performed for cokes with various ash contents.

An important factor contributing to coke degradation is a change of coal structure in the coke and its graphitization being advanced. It was found that coke lumps, both those removed from nuzzles of the blast furnace, and those after the thermo-abrasion tests indicate higher graphite content than the batch coke [5].

In order to evaluate identification of the polycrystalline phases in the researched materials, X-ray crystallography was used. After the research data were processed and accurate results received, it was possible to determine the size of $L_{a}$ and Lc crystallites and interplanar distances for planes of (002) type.

The width of $L_{a}$ crystallite (mean size of the ordered area in the direction of the axis and crystallites) for the analyzed coke samples was calculated based on the Warren and Bodensteine's model:

$L_{a}=\frac{k \lambda}{\beta \cos \theta}$

where:

$k$ - factor of proportionality (here: $k=1.77$ )

$\lambda$ - radiation wavelength,

$\theta$ - scattering angle,

$\beta$ - reflection half-width.

The calculation of the crystallite size $L_{c}$ (the average size of the region ordered in the direction of the $C$ axis) for the analyzed coke samples was made according to Scherrer's formula [5]:

$L_{c}=\frac{k \lambda}{\beta \cos \theta}$

where:

$k$ - factor of proportionality (here: $k=1$ ). 
Whereas, for calculating the interplanar length, do02, for the analyzed coke samples, the relationship below was used:

$d_{002}=\frac{n \lambda}{2 \sin \theta}$

where:

$n$ - reflection order (here: $n=1$ ).

At the same time, it was assumed that X-ray radiation is scattered in the amorphous regions and in the crystalline diffraction regions is being diffracted, according to the Bragg's law.

There were performed research studies to determine the impact of temperature on the amount of crystalline and amorphous phases and the size of crystallites in the samples of coke. Coke samples collected at weighting and batching plant were subject to research tests. Subsequently, they were treated in the blast furnace and tested in the pre-tuyère chamber model. Examples of diffractograms of the test samples in the initial state with peaks characteristic for graphite during diffraction carried out by using cobalt anode lamp are shown in Figures 2 - 5.

Particular coke lumps being subject of the analysis in each of the states were collected from the same group of samples. Laboratory practice confirms changes in the coke structures, mainly due to fluctuations in the petrographic composition of batch coals, which varies not only in different deposits of the same mine, but even in the same deck. The size of crystallites in the coke extracted from nozzles depends on the size of crystallites in the coke being loaded into the blast furnace and it increases in the blast furnace. This increase depends on (changing) heat conditions in the blast furnace, and also on the petrographic characteristics of the batch coal used in the coking plant. By comparing the results received when heating the coke in the blast furnace and during thermos-abrasion tests, it can be easily observed that the coke residence time at high temperatures (of approx. $1700^{\circ} \mathrm{C}$ ) is of great importance.

By analysing the obtained results, it can be stated that samples collected from the blast furnace - the first group (that means samples treated at very high temperatures - exceeding $2000^{\circ} \mathrm{C}$ for quite a long time, namely for 5 - 7 hours) were characterized with the highest degree of crystallization. The lowest level of graphitization indicated samples of coke being collected directly from the coking plant - the third group, which were not subject to any thermal processing (despite the production process). Samples from the midlevel group with average degree of crystallization are cokes, which were subject to the thermos-abrasion tests performed at increased temperatures - the second group.

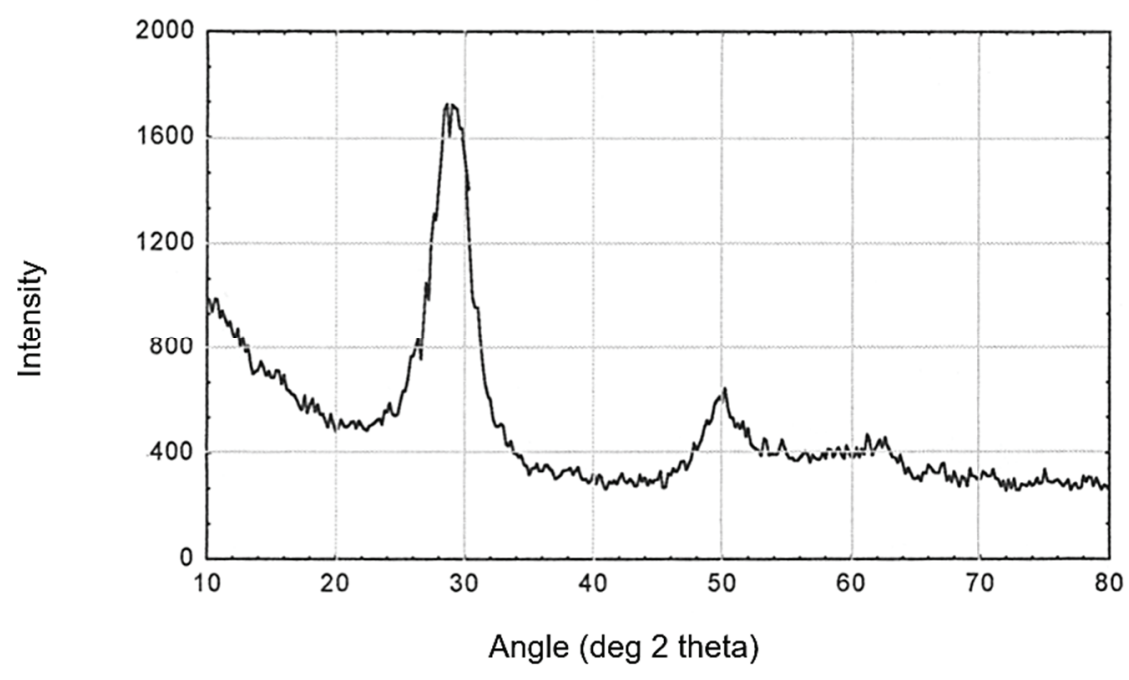

Figure 2 Diffractogram coke form the Steel Mill's Burdening Shop 


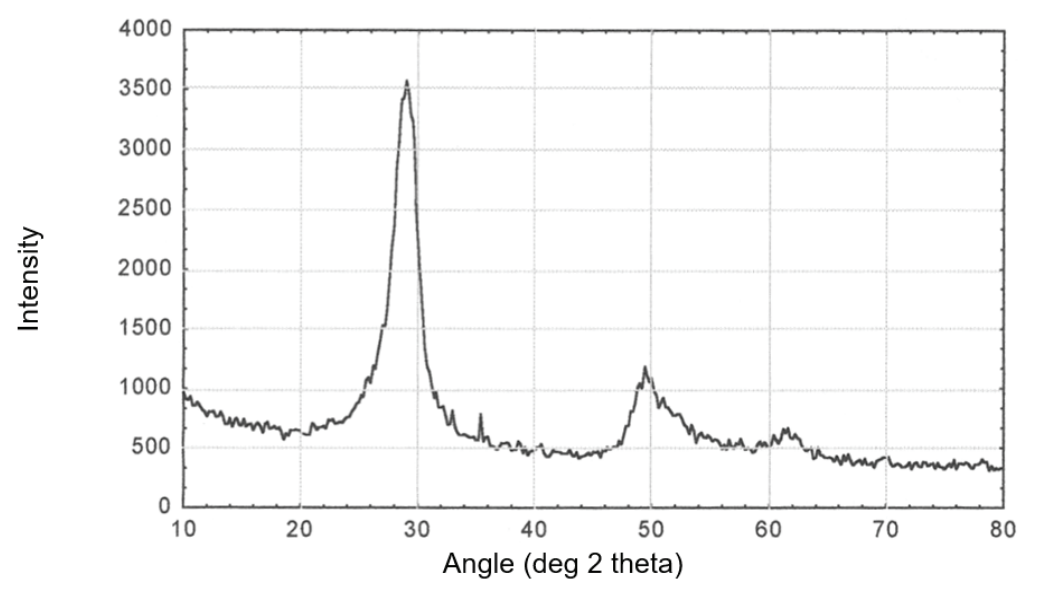

Figure 3 Diffractogram coke form the blast-furnace $\mathrm{Nr} 1$ tuyère level

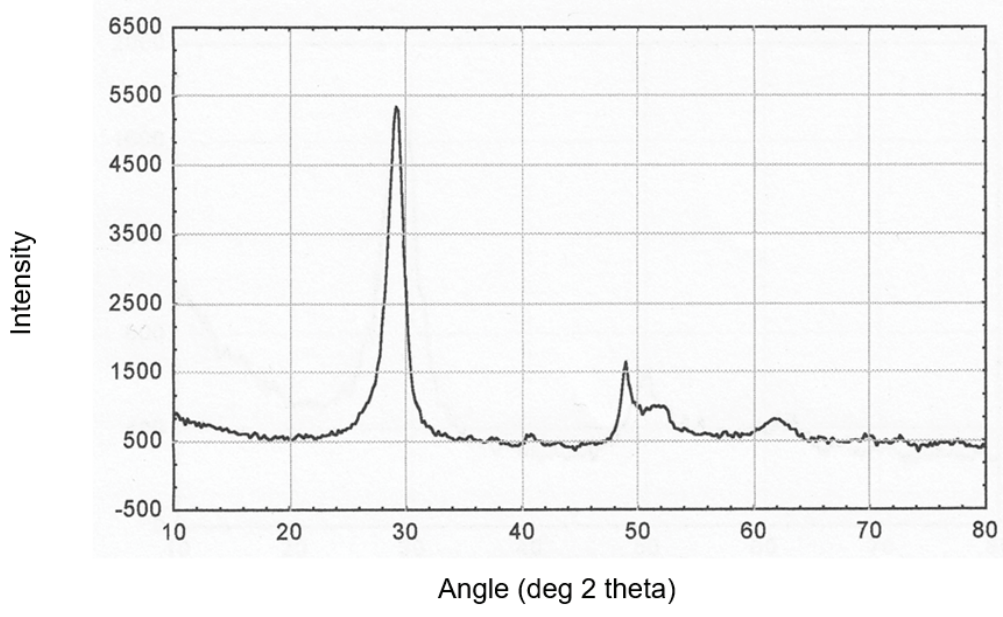

Figure 4 Diffractogram coke form the blast-furnace $\mathrm{Nr} 3$ tuyère level

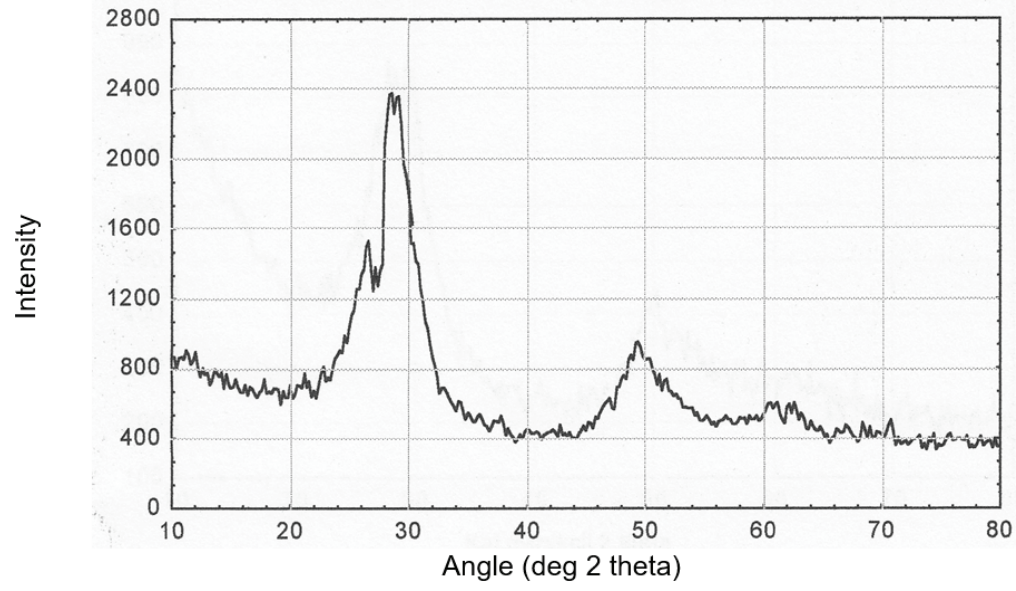

Figure 5 Diffractogram coke form thermal abrasion testing at elevated temperatures

It can, therefore, be concluded that:

a) the samples of group I have the largest crystallites varying in the range of:

width, $L_{a}: 36.704 \div 49.982 \mathrm{~nm}$, height, $L_{c}: 21.244 \div 28.238 \mathrm{~nm}$; 
b) the samples of group II have the intermediate crystallites varying in the range of:

width, $L_{a}: 22.148 \div 29.866 \mathrm{~nm}$, height, $L_{c}: 12.512 \div 16.874 \mathrm{~nm}$;

C) the samples of group III have the smallest crystallites varying in the range of:

width, $L_{a}: 11.228 \div 20.18 \mathrm{~nm}$, height, $L_{c}: 6.341 \div 11.36 \mathrm{~nm}$.

The interplanar distance $d_{(002)}$ varies in the range of $0.3558387 \div 0.3921946 \mathrm{~nm}$. For the first group of the examined cokes, it changes only slightly and is the closest to that occurring in graphite, which is indicative of a high degree of crystallinity of these samples.

Based on the fractal curves, the value of pore fractal, $D_{p}$; the fractality range, $\alpha$ and $\zeta$; and the reduced length of the chord, Ir, of the fractal area were determined for samples from from the Steel Mill's Burdening Shop and from thermal abrasion testing at elevated temperatures. The results obtained from the SAXC analysis of the curves are summarized in Table 1.

Table 1 The dimensions of pore fractal, $D_{p}$; the mean length of the chord, $l_{r}$; and the limits $\alpha$ and $\zeta$ of the fractality range

\begin{tabular}{|c|c|c|c|c|c|}
\hline Sample & Place of test & $D_{\boldsymbol{p}}$ & $\boldsymbol{\alpha}(\mathrm{nm})$ & $\zeta(\mathrm{nm})$ & $\boldsymbol{I}_{\boldsymbol{r}}(\mathrm{nm})$ \\
\hline \multirow{2}{*}{$\begin{array}{c}\text { (1) from the Steel Mill's Burdening } \\
\text { Shop }\end{array}$} & sample surface & 2.25 & 0.28 & 3.39 & 1.72 \\
\cline { 2 - 6 } & sample centre & 2.2 & 0.28 & 3.63 & 1.90 \\
\hline \multirow{2}{*}{$\begin{array}{c}\text { (2) from thermal abrasion testing at } \\
\text { elevated temperatures }\end{array}$} & sample surface & 2.5 & 0.28 & 4.47 & 2.68 \\
\cline { 2 - 6 } & sample centre & 2.4 & 0.28 & 5.89 & 2.96 \\
\hline
\end{tabular}

For the test coke, the average size of pore structure fractals of $D_{p}$ samples are (1) -2.2125 and (2) -2.45 . This indicates that the surface is highly porous with a network of interconnected pores. The average reduced-chord length of the porous region ranges from $0.172 \mathrm{~nm}$ to $0.296 \mathrm{~nm}$.

Boundaries: $\alpha$ of the fractal range is 0.28 , while $\zeta$ ranges from $0.039 \mathrm{~nm}$ to $0.589 \mathrm{~nm}$. For the test samples, differences of nanoporosities between the outer and inner surfaces of the coke lumps are very small and range from 0.05 to 0.1 .

\section{CONCLUSION}

Problems on coke applications in blast furnace processes are subject to research studies and discussions, both scientists and industry professionals. This has been confirmed in numerous publications. However, it is undeniable that the most crucial property of blast furnace coke is its mechanical strength [7].

The most common method for predicting mechanical strength properties of the coke is the MICUM drum method. Despite complexity of this measurement (for example - the need to select grain size of the coke, being subject to research tests), this method does not provide information whether in cool areas of the blast furnace (below $800{ }^{\circ} \mathrm{C}$ ) properties of the coke are being improved or deteriorated (the mechanical strength of the coke increases or decreases). On the other hand, this method does not allow to measure the strength properties of coke at high temperatures. The Nippon Steel method, which determines properties of coke at increased temperatures $\left(1100^{\circ} \mathrm{C}\right)$, is becoming more common and widely used. The conducted research tests allowed to examine the availability of assessing the coke in a device modelling conditions prevailing in the blast furnace, namely at temperatures in the range of $1500-2000{ }^{\circ} \mathrm{C}$. Based on these research tests, it was found out that a decrease of the thermos-abrasion index improves the air-permeability coefficient of the batch in the blast furnace. 
Furthermore, it was stated that samples collected in the blast furnace - the first group (i.e. samples treated thermally at very high temperatures - exceeding $2000{ }^{\circ} \mathrm{C}$ ) were characterized by the highest level of crystallization. Whereas, the lowest degree of crystallization is demonstrated by coke samples taken directly from the coking plant - the third group, which have not undergone any thermal processes (except for the production process). Samples from the mid-level group with average degree of crystallization are cokes, which were subject to the thermo-abrasion tests performed at increased temperatures.

By applying the SAXS method, it is possible to determine nanostructure parameters for the blast furnace coke. At the same time, it was stated that the surface of the test materials is highly porous with a network of interconnected pores.

\section{ACKNOWLEDGEMENTS}

This article was prepared within the framework of financing the statutory activity from grants to maintain research potential BS/PB-2-204-301/2005/P Faculty of Production Engineering and Materials Technology, Czestochowa University of Technology.

\section{REFERENCES}

[1] GABZDYL, Wiesław. Mineralogy and petrography. Gliwice, Silesian University of Technology, University Script. 1987. p. 311.

[2] NISCHI, Tetsu, HARAGUCHI, Hiroshi and OHURA, Toshiaki. Deterioration of coke strength by $\mathrm{CO}_{2}$ at high temperature. ISIJ. 1987. vol. 73, no. 15, pp. 67-74.

[3] KONSTANCIAK, Anna. Physicochemical changes of coke in the blast furnace process. Habilitation Thesis. Częstochowa. 2013, p. 134.

[4] SABELA, Władysław and STEC, Roman. Selected issues from blast furnace technology. Częstochowa, Pub. House of Czestochowa University of Technology. 1989, p. 124.

[5] ASHBY, Michael, SHERCLIFF, Hugh and CEBON, David. Material Engineering. Łódź, Pub. House Galaktyka. 2011, p. 288.

[6] PRZEDMOJSKI, Jan. X-ray research methods in material engineering. Warszawa, WNT 1990, p. 183.

[7] BROZOVA, Silvie, INGALDI, Manuela and SPERLIN, Ivan, Economical aspects of high-temperature heating utilization for industrial waste treatment. In METAL 2014: 23rd International Conference on Metallurgy and Materials. Ostrava: TANGER, 2014, pp. 377-382. 